\title{
Biological anomalies in the sugarcane leafhopper, Pyrilla perpusilla (Walker) due to parasitism by Fulgoraecia melanoleuca (Fletcher) (Lepidoptera: Epipyropidae)
}

Tarun Sharma and P. S. Shera* ${ }^{*}$

\begin{abstract}
Background: Fulgoraecia melanoleuca (Fletcher) (Lepidoptera: Epipyropidae) (=Epipyrops or Epiricania melanoleuca) is an important koinobiont nymphal and adult ectoparasitoid of sugarcane leafhopper, Pyrilla perpusilla (Walker) (Hemiptera: Lophopidae). The study aimed to evaluate whether and to what extent this parasitoid effects the fitness of immature (five nymphal stages) and adult ( 0 and $\$$ ) stages of its host $P$. perpusilla.

Results: The nymphal mortality was significantly more in the younger nymphs, and it decreased as the host aged. The exposure of the first stage host nymphs to the parasitoid resulted in 100\% mortality. However, the nymphal mortality rates in second, third, fourth and fifth nymphal stage were 94.0, 75.0, 38.0 and 41.0\%, respectively. Furthermore, the longevity of surviving nymphs was prolonged significantly in the later stages. None of the parasitized first to fourth stage nymphs survived as normal adult. In case of the parasitized fifth nymphal stage, $18.0 \%$ adults were normal; however, their longevity was comparatively shorter than their un-parasitized counter parts. When male and female adults of leafhopper were offered to the parasitoid, significant differences were found in mortality of parasitized and un-parasitized adults for both sexes. Further, parasitoid-induced prolongation in the longevity of the surviving parasitized adults was also observed.
\end{abstract}

Conclusions: Overall, the parasitoid F. melanoleuca had detrimental effects on host fitness and thus played a significant role as a biological control agent in suppressing the sugarcane leafhopper population. This study will clarify host-parasitoid relationship, developing mass rearing protocol under laboratory conditions and implementing effective strategies for augmentative releases of parasitoids in biological control program against $P$. perpusilla in sugarcane ecosystem.

Keywords: Pyrilla perpusilla, Fulgoraecia melanoleuca, Epipyropidae, Parasitism, Biology

\section{Background}

The sugarcane leafhopper, Pyrilla perpusilla (Walker) (Hemiptera: Lophopidae) is a serious sucking pest widely distributed in Asian countries including India (Kumar et al. 2015; Mahesh et al. 2019), China (Liang

*Correspondence: psshera@pau.edu

Department of Entomology, Punjab Agricultural University, Ludhiana 141004, India
1997), Nepal (Neupane 1976), Pakistan (Rasul et al. 2014; Yaseen et al. 2021), Sri Lanka (Ganehiarachchi and Fernando 2006), Thailand (Fennah 1963), Cambodia (Liang 1997) and Vietnam (Emeljanov 2018). Besides sugarcane, it has also been reported on other alternate host crops like wheat, maize, sorghum, pearl millet, barley, bitter gourd, sponge gourd, okra, watermelon, pumpkin, rice, oat, peas, bamboo and wild grasses (Ganehiarachchi and Fernando 2006). Both nymphs and adults suck the phloem sap from undersurface of the leaves near midrib, 
resulting in yellowing and in case of heavy infestation, the leaves gradually turn pale in color and dry up. The development of sooty mold on the leaves due to secretion of honeydew reduces the photosynthetic activity of the plant. The early infestation of $P$. perpusilla during cane growth period adversely affects the cane yield. However, late infestation significantly affects the sucrose content of the cane (Puri and Sidharth 2001). The cane juice becomes high in glucose content and on gur making (concentrated product of cane juice); it gives a soggy mass which does not solidify properly thus reducing its economic value (Chaudhary and Sharma 1988).

Several biological control agents have been recorded against P. perpusilla worldwide. Among these, Fulgoraecia melanoleuca (Fletcher) (=Epipyrops or Epiricania melanoleuca Fletcher) (Lepidoptera: Epipyropidae) is an important nymphal and adult ectoparasitoid of $P$. perpusilla endemic to India (Srikanth et al. 2016), Sri Lanka (Ganehiarachchi and Fernando 2006) and Pakistan (Akhtar et al. 2014; Yaseen et al. 2021). After hatching from eggs, its larvae catch and hold the passing pyrilla nymph (Fig. 5) or adult (Fig. 6) by its hooked claws. The larvae penetrate the host cuticle with its sharp mandibles and suck the body fluids. After the completion of larval period, the larvae leave the host body and spin white, oval-shaped cocoon on the leaves before pupation. The host pyrilla dies as soon as it is released by the parasitoid (Rajak et al. 2006).

A suitable host stage or host quality plays a key role in the fitness of the parasitoid progeny (Hagvar and Hofsvang 1991; Farahani et al. 2016). The juvenile of koinobiont parasitoids upon hatching permits the host to continue its development while feeding on it (Haeselbarth 1979; Cameron et al. 2005). The length of this delay, or lag, in host death is often determined by the age or size of the host when it is parasitized (Godfray 1994). Our earlier study indicated that later nymphal stages and adult female of $P$. perpusilla were more suitable as the parasitoid gains greater fitness return and yield more female progeny on these host stages (Sharma 2021) but the effects of host life-stages at the time of parasitism on its future fitness, survival and life history traits need to be investigated. The objective of this study was to assess the biological anomalies in the different age groups of nymphs and adults (male and female) of sugarcane leafhopper owing to parasitism by F. melanoleuca.

\section{Methods}

\section{Plant material}

The seed sets of sugarcane variety (Co 238) were sown in earthen pots and under field conditions at the Entomological Research Farm, Punjab Agricultural University, Ludhiana $\left(30^{\circ} 90^{\prime} 02^{\prime \prime} \mathrm{N}, 75^{\circ} 80^{\prime} 33^{\prime \prime} \mathrm{E}, 247 \mathrm{~m}\right)$. The sugarcane crop was kept without insecticide application throughout the cropping season (Anonymous 2019) and leaves were used for the rearing of insect cultures.

\section{Rearing of $P$. perpusilla}

The eggs, nymphs, and adults of $P$. perpusilla were collected from sugarcane fields. The culture of $P$. perpusilla (nymphs and adults) was maintained on sugarcane leaves using a new technique in the laboratory under controlled temperature $\left(27 \pm 2^{\circ} \mathrm{C}\right)$ and relative humidity $(70 \pm 5 \%)$ conditions. The sugarcane leaves were kept in conical flasks $(250 \mathrm{ml})$, filled with water. The flasks (2-4 in number) were placed in aluminum screen cages $(30 \mathrm{~cm} \times 30 \mathrm{~cm} \times 45 \mathrm{~cm})$. Field collected nymphs and adults of pyrilla were released into each cage. Flasks with fresh sugarcane leaves were changed at a regular interval of 2-4 days (in summer) and 4-7 days (in winter) to provide fresh food for pyrilla nymphs and adults. The maintained culture of $P$. perpusilla was used for rearing of $F$. melanoleuca and conducting different experiments.

\section{Rearing of $F$. melanoleuca}

Different life stages of $F$. melanoleuca, i.e. egg masses, cocoons (pupae) and adults were collected from sugarcane fields during post-monsoon season (August-September, 2019) having an average temperature around $30{ }^{\circ} \mathrm{C}$. The parasitoid was reared on the $P$. perpusilla culture maintained on sugarcane leaves kept inside the flasks placed in aluminum cages. The emerging parasitoid adults from the cocoons (pupae) were differentiated on the basis of morphological characters. Males have bipectinate antenna and an off white outer margin of forewing and hind wing while females have thread like antenna with grey black forewing and dark grey hind wing (Kumar et al. 2015). Freshly emerged males and females were paired and kept in aluminum cages for mating and subsequent egg laying on sugarcane leaves. A cotton wool swab was hung in each cage after dipping in $10 \%$ honey solution as a food for the parasitoid adults. The sugarcane leaves with freshly laid eggs were collected and placed in the insect screen cages having pyrilla population (nymphs and adults) for parasitism. The freshly hatched eggs from the maintained culture were utilized for further experimentations.

\section{Biological studies (host nymphs)}

For studying the anomalies in the parasitized nymphs, 200 individuals from each of five nymphal stages (1st, 2nd, 3rd, 4th and 5th) of P. perpusilla were obtained from the culture maintained under laboratory conditions. They were released in separate aluminum screen cages $(30 \mathrm{~cm} \times 30 \mathrm{~cm} \times 45 \mathrm{~cm})$ on sugarcane leaves kept in water filled conical flasks with the help of an aspirator. 
The host insects were exposed to the parasitoid by stapling the sugarcane leaf bit having egg mass (eggs about to hatch) of $F$. melanoleuca to sugarcane leaves in cages. Twenty individuals of each stage ( 5 replicates; $n=100$ ) showing signs of parasitism were taken and kept in the separate plastic vials $(3.5 \mathrm{~cm}$ diameter $\times 10.0 \mathrm{~cm}$ height) to record different parameters on host $P$. perpusilla. Small pieces of sugarcane leaves were provided in each vial as food for pyrilla nymphs and adults. For maintaining leaf turgidity, leaves were enfolded using water-soaked cotton wool on one side. Observations were recorded on the mortality of host as nymphs, intermediates (nymph-adult or adult-nymph) or weak adults (not fully developed or less active), nymphal longevity and survival as normal adults. A set of un-parasitized nymphs was also kept for comparison.

\section{Biological studies (host adults)}

To determine parasitism effects in adults of $P$. perpusilla, study was carried out on both males and females. Two hundred individuals were released in the cages on sugarcane leaves. They were parasitized manually and 20 individuals of each gender ( 5 replicates; $n=100$ ) showing signs of parasitism were taken and kept in the separate plastic vials $(3.5 \mathrm{~cm}$ diameter $\times 10.0 \mathrm{~cm}$ height) to record the observations on mortality and longevity of adults. A set of un-parasitized adults was also kept for comparison.

\section{Data analysis}

All data are presented as mean \pm standard error of the mean (SE). The percentage data on mortality of parasitized nymphs and survival as normal adults were arcsine transformed prior to analysis of variance (ANOVA) for normal distribution and meet the assumptions of ANOVA. The values of 0 and $100 \%$ were substituted by $1 / 4 n$ and $100-1 / 4 n$, respectively, before statistical analysis. Data on longevity of parasitized nymphs were normally distributed (goodness-of-fit test) and were analyzed using ANOVA. The means were separated using a Tukey's test. Survival and longevity of parasitized and unparasitized adults were compared using student's $t$-test to calculate the significance level. All statistical tests were carried out using IBM SPSS 22.0 for Windows (IBM Corporation, Armonk, New York, USA).

\section{Results}

Parasitism effects on $P$. perpusilla nymphs Mortality as nymphs, intermediate forms or weak adults

Significant differences were observed in the nymphal mortality when nymphs of various ages were offered to the parasitoid $(F=1485.0, d f=5,24, p<0.0001)$. The mortality was $100 \%$ in the first nymphal stage, followed by the second $(94.00 \pm 1.00 \%)$, third $(75.00 \pm 1.58 \%)$, fifth $(41.00 \pm 1.29 \%)$ and fourth stage $(38.00 \pm 1.22 \%)$ nymphs (Fig. 1). The mortality as intermediate forms was 51.0, 18.0, 11.0 and 3.0\% in fourth, third, fifth and second nymphal stages, respectively $(F=126.76, d f=4$, $20, p<0.0001)$. After completing the nymphal period, the death in parasitized nymphs as weak adults was also observed $(F=59.84, d f=4,20, p<0.0001)$. The percentage mortality as weak adult was 30.0, 11.0, 7.0 and 3.0\% in fifth, fourth, third and second nymphal stages, respectively (Fig. 1).

\section{Nymphal longevity}

The longevity of nymphs parasitized in the later stages (third, fourth and fifth) was prolonged significantly than in un-parasitized nymphs $(F=269.72 ; d f=4,20$; $p<0.0001)$ and the highest prolongation $(+8.11$ days $)$ being in the fourth parasitized nymphs. While the developmental period of nymphs parasitized in the second stage was comparatively shorter ( -8.32 days) as against un-parasitized nymphs (Table 1 ).

\section{Survival as normal adults}

None of the nymph parasitized at the first, second, third, and fourth stage survived as normal adult. They died as weak nymphs, nymph-adult intermediates, or weak adults. In case of 5 th parasitized nymphs, $18.00 \pm 1.29 \%$ adults were normal. While $100 \%$ survival was observed in un-parasitized nymphs $(F=8619.74, d f=4,20$, $p<0.0001$; Fig. 2).

\section{Longevity of surviving host adults}

Irrespective of host stage, females survived for a longer duration as compared to males (Fig. 3). Significantly lower longevity was found in adult females from parasitized 5th nymphal stage than on un-parasitized nymphs $(t=12.94, p=0.0001)$. However, the longevity of adult males from parasitized 5th nymphal stage did not differ significantly from un-parasitized ones $(t=1.68$, $p=0.0659$ ).

\section{Parasitism effects on P. perpusilla adults Mortality}

When male and female pyrilla adults were offered to the parasitoid, significant differences were observed in mortality of parasitized and un-parasitized adults for both the sexes (for male, $t=94.00 ; p<0.0001$ and for female, $t=56.92 ; p<0.0001$ ). The parasitism resulted in 94.0 and $90.0 \%$ mortality of adult males and adult females, respectively. However, no mortality was recorded in un-parasitized adults for both the sexes (Fig. 4). 


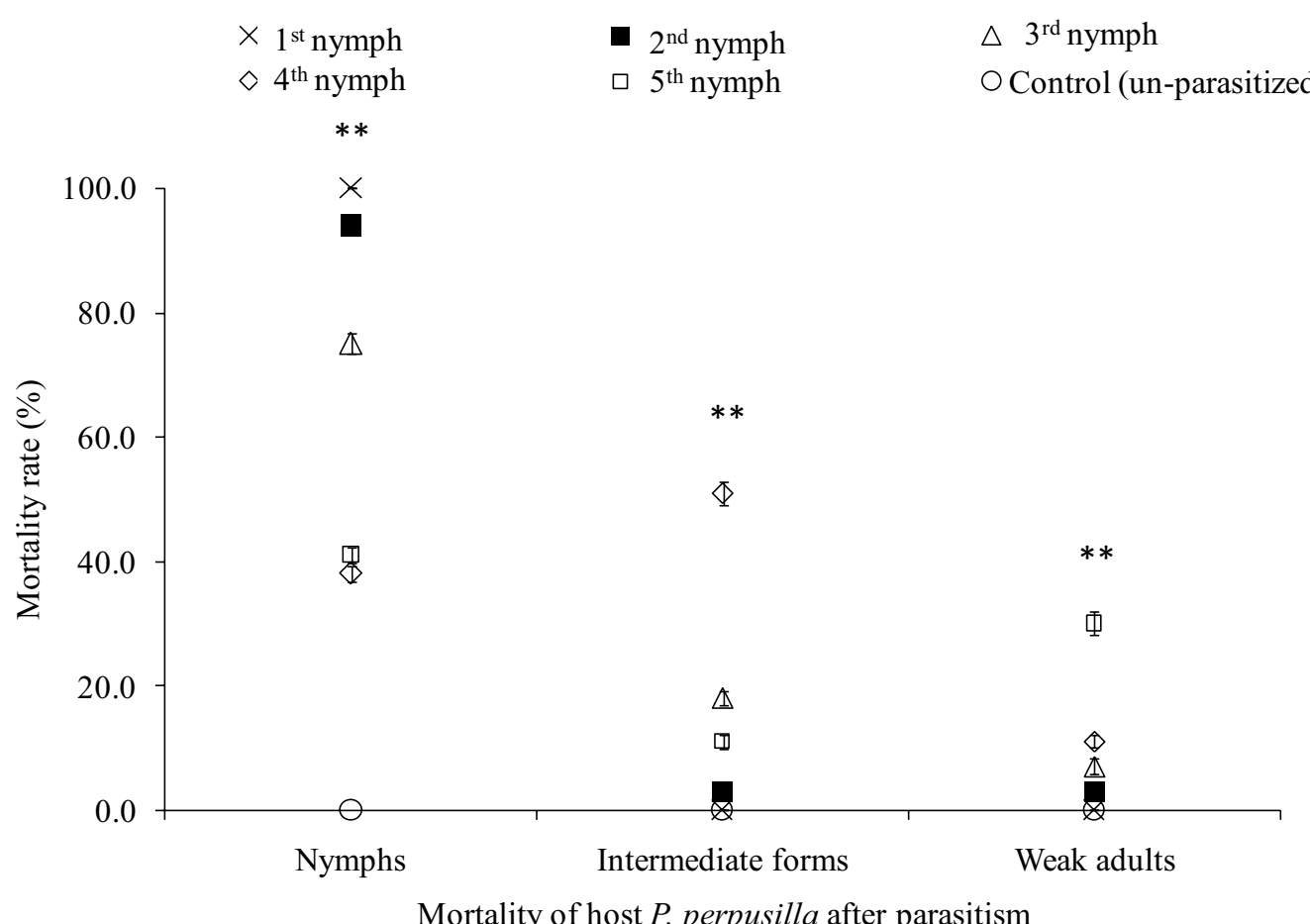

Fig. 1 Mortality of host P. perpusilla as nymphs, intermediate forms (nymph-adult or adult nymph) or weak adults when various nymphal stages were offered to parasitoid F. melanoleuca for parasitism as against un-parasitized nymphs; "**" within a column indicate $(p<0.05)$ significant difference; the results are presented as the means \pm SEs

Table 1 Effect of parasitism by F. melanoleuca on the longevity of P. perpusilla nymphs

\begin{tabular}{lll}
\hline $\begin{array}{l}\text { Host (nymphs) stage } \\
\text { at time of parasitism }\end{array}$ & $\begin{array}{l}\text { Longevity of nymphs } \\
(\text { mean } \pm \text { SE) in days }\end{array}$ & $\begin{array}{l}\text { Increase }(+) \text { or } \\
\text { decrease }(-) \text { in days } \\
\text { over control }\end{array}$ \\
\hline st & $* *$ & $* *$ \\
$2 \mathrm{nd}$ & $\begin{array}{l}19.00 \pm 0.45 \mathrm{a} \\
(n=6)\end{array}$ & -8.32 \\
& $\begin{array}{l}31.67 \pm 0.21 \mathrm{C} \\
(n=25)\end{array}$ & +4.35 \\
3rd & $\begin{array}{l}35.43 \pm 0.43 \mathrm{~d} \\
(n=62) \\
32.02 \pm 0.41 \mathrm{C} \\
(n=59)\end{array}$ & +8.11 \\
4th & +4.70 \\
5th & $\begin{array}{l}27.32 \pm 0.30 \mathrm{~b} \\
(n=100)\end{array}$ \\
Control (un-parasitized) & - \\
\hline
\end{tabular}

${ }^{* *}$ No successful parasitism in 1st nymphal stage of $P$. perpusilla; Means within column followed by different letters are significantly different $(p<0.05)$

\section{Adult longevity}

Irrespective of host sex, parasitized host female survived for a longer duration than the parasitized males. However, the parasitism prolonged the longevity of surviving host adults significantly for both sexes (for male, $t=12.40 ; p<0.0001$ and for female, $t=7.23 ; p<0.0001$ ).
The longevity of parasitized males was significantly longer (+ 7.15 days) than the un-parasitized males. Similarly, parasitized females survived for a longer period $(+5.26$ days) as against un-parasitized ones (Table 2$)$.

\section{Discussion}

The proper understanding of biological relationship between host and parasitoid is a key to develop an ecofriendly and effective biocontrol program. The koinobiont parasitoid, $F$. melanoleuca is a key mortality agent of $P$. perpusilla nymphs and adults under the field conditions in India due to its short life cycle, higher reproductive rate, an excellent searching ability and optimally synchronized life cycle with its host development (Seneviratne and Kumarasinghe 2002). Hence, it possesses an enormous potential in the bio-suppression of sugarcane leafhopper. Parasitism occurs at any nymphal stage, the effects of host life stage at the time of parasitism on the fitness traits of adults and advanced nymphal stages of $P$. perpusilla were investigated. The present studies showed that the nymphal mortality was significantly more in younger nymphs and it decreased as the host aged. The exposure of first nymphal stage to the parasitoid resulted in $100 \%$ mortality within 2 days before any signs of parasitism which may be due to parasitoid-inflicted injuries 

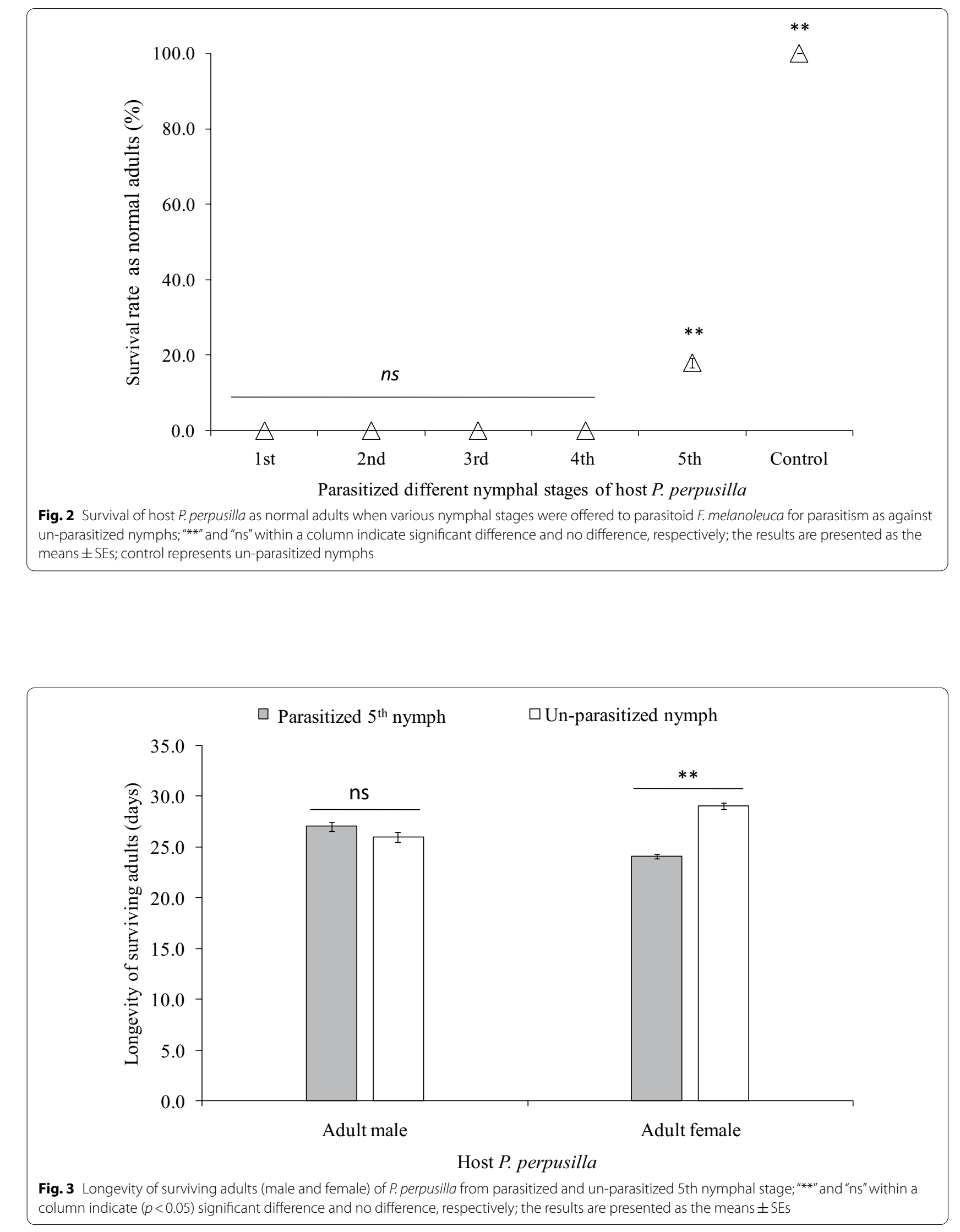


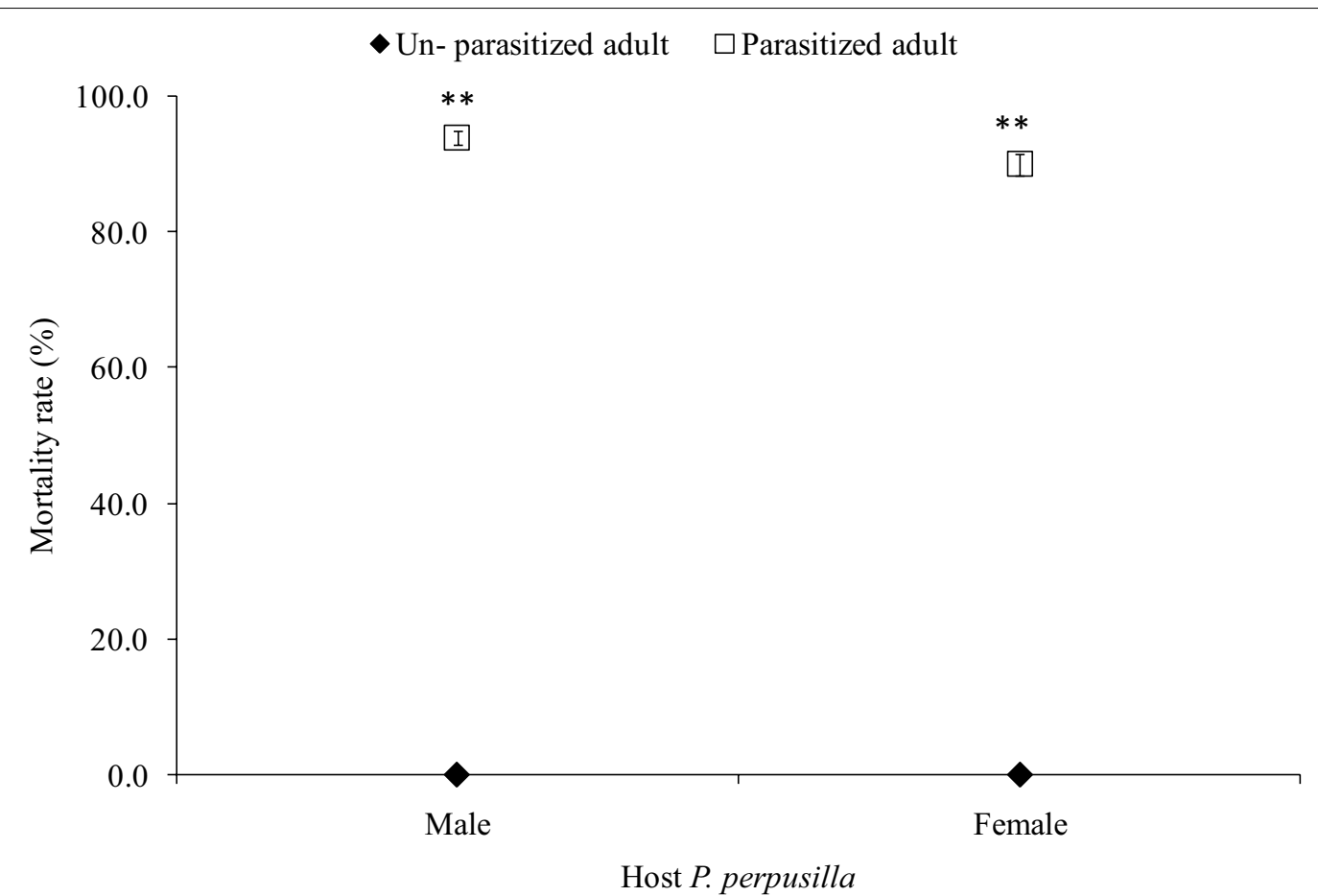

Fig. 4 Mortality of host $P$. perpusilla when male and female adults were offered to parasitoid $F$. melanoleuca for parasitism as against un-parasitized nymphs; ${ }^{\prime * * * " ~ w i t h i n ~ a ~ c o l u m n ~ i n d i c a t e ~}(p<0.05)$ significant difference; the results are presented as the means \pm SEs

Table 2 Effect of parasitism by F. melanoleuca on the longevity of P. perpusilla adults

\begin{tabular}{llll}
\hline $\begin{array}{l}\text { Host stage } \\
\text { at time of } \\
\text { parasitism }\end{array}$ & \multicolumn{2}{l}{ Longevity (Mean \pm SE) in days } & $\begin{array}{l}\text { Increase }(+) \\
\text { in days over } \\
\text { un-parasitized } \\
\text { adult }\end{array}$ \\
\hline Adult male & $30.44 \pm 0.44 \mathrm{~b}$ & $23.29 \pm 0.38 \mathrm{a}$ & +7.15 \\
Adult female & $34.64 \pm 0.59 \mathrm{~b}$ & $29.38 \pm 0.42 \mathrm{a}$ & +5.26 \\
\hline
\end{tabular}

* Mean of 5 replications; Means within row followed by different letters are significantly different $(t$ test, $p<0.05)$

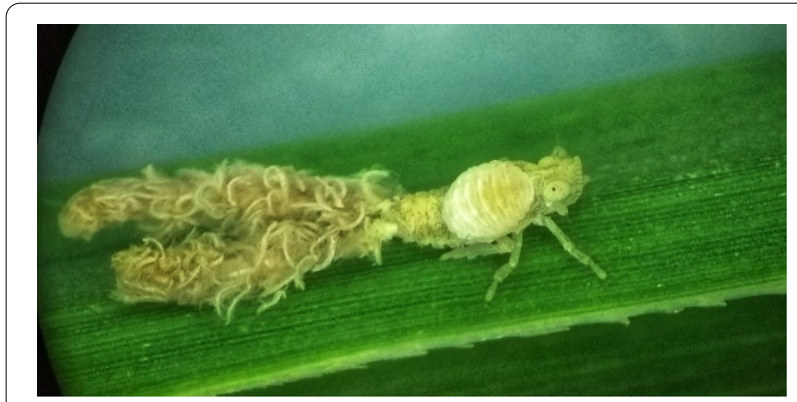

Fig. 5 Parasitized nymph of sugarcane pyrilla

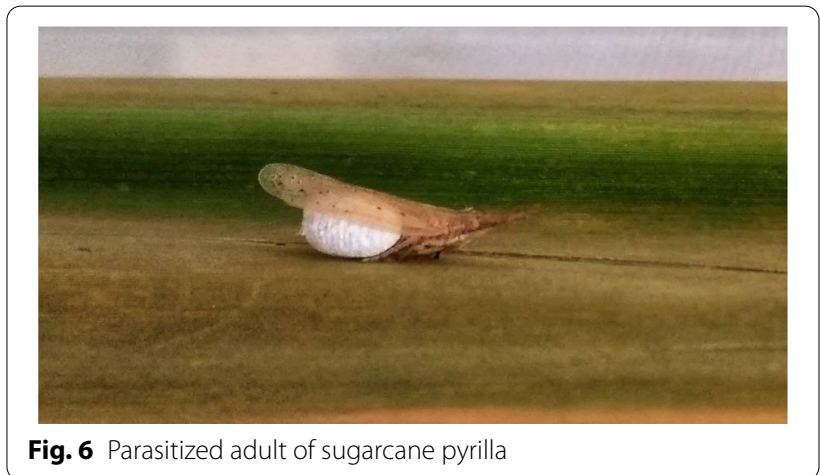

(Bal et al. 1990). The parasitism in initial nymphal stages coincided with precocious death of the host. High mortality owing to injuries caused by the parasitoid was reported by Mukerji and Venkataraman (1948). Besides, the early nymphs might have not tolerated the parasitoid feeding as compared to later nymphs and died as nymphs only (Figs. 5, 6).

It was also observed that all the parasitized individuals died as weak nymphs, nymph-adult intermediates, or weak adults when first to fourth nymphal stages were offered to the parasitoid for parasitism which is crucial to optimize the augmentative releases of this parasitoid 
under field conditions. Obtained results support the findings of Misra and Krishna (1986) that the hosts do not die immediately although they succumb due to parasitism with time. Dhaliwal (1982) also observed that although parasitized nymphs did not die of parasitism immediately on the completion of development of parasitoid larvae, yet they could not survive and develop into adults. However, in case of the parasitized fifth nymphal stage, only $18 \%$ adults were normal. It is worthwhile to mention that $F$. melanoleuca is koinobiont ectoparasitoid that allows the development of its host also. Being robust and active, last nymphal stage might have tolerated the feeding activity of parasitoid and molted as normal adults as compared to younger nymphs. Moreover, older hosts had stronger immune defenses than younger ones (Strand and Pech 1995). The other possible reason could be that parasitoid might have detached and pupated after getting adequate resources for its development from the fifth nymphal stage. As a result, few nymphs parasitized at 5th stage completed their development and survived as normal adults. This is also clear from another study in which larval period of $F$. melanoleuca on fifth nymphal stage of $P$. perpusilla was comparatively less as compared to penultimate 4th nymphal stage (Sharma 2021). Similar findings have also been reported by Dhaliwal (1982) that some of nymphs parasitized in the advanced stage did not manifest parasitism and parasitoid could continue development on the resulting adults when symptoms also appeared. On the other hand, Bindra and Brar (1978) have reported the emergence of normal adults from parasitized penultimate nymphs.

The present results showed that prolongation in development period of nymphs parasitized in the later stages (third to fifth), while the longevity was comparatively less in parasitized second stage nymphs as against unparasitized nymphs. It is worthwhile to mention that all the first stage nymphs died before showing any signs of parasitism. The length of this delay, or lag, in host death is often determined by the age or size of the host when it is parasitized and by the cue from the host to the juvenile parasitoid that the host contains sufficient resources for the parasitoid to complete its development (Godfray 1994). It is vital that the host is not killed until it can sustain the nutritional requirements of the parasitoid for its growth and survival (Harvey et al. 2000). The parasitoid-induced prolongation in the longevity of the nymphs might have led to feeding of pyrilla nymphs for additional days, but probably the feeding rate of parasitized nymphs may be lower than normal feeding due to weakness caused by parasitism. The koinobiont parasitoids often exhibit high flexibility in their development; their larvae shorten or prolong the developmental period depending on the host quality at parasitization (Kohyama et al. 2017). Bindra and Brar (1978) and Brar (1978) also reported that parasitized penultimate nymphs took longer time to develop into adults than by un-parasitized ones.

Obtained findings also showed that the surviving female adults from parasitized fifth nymphal stage survived for shorter duration than adults from un-parasitized nymphs. Moreover, fecundity of these adults was also comparatively lower than adults from un-parasitized ones (Bal et al. 1990). It is worthwhile to mention that $100 \%$ mortality was observed in parasitized first to fourth nymphal stages and there was no survival as normal adults.

When male and female adults of $P$. perpusilla were offered to the parasitoid, significant mortality in both sexes were recorded due to parasitism than the un-parasitized ones. Further, parasitoid-induced prolongation in the longevity of the surviving adults was also observed. The increase in longevity of parasitized pyrilla adults can lead to feeding for additional days, but probably the feeding rate of such adults might be lower than normal feeding due to weakness caused by parasitism. Many solitary koinobiont parasitoids are known to decrease the consumption of food by its host considerably, as compared with healthy hosts, and are therefore considered good agents for biological control programs (Rohlfs and Mack 1983). The fecundity of the parasitized females was also lower $(\sim 25 \%)$ than the un-parasitized ones. Similar findings have been reported by Gupta (1940), and Mukerji and Venkatraman (1948). However, Brar and Bains (1979) reported no effect of parasitism on reduction in the longevity of parasitized adults.

\section{Conclusions}

The nymphal mortality was significantly higher in the younger nymphs and it decreased in the older nymphal stages. All the parasitized $P$. perpusilla nymphs died in the form of nymphs, nymph-adult intermediates, and weak adults except in 5th nymphal stage. However, it lasted longer time to develop into adult than the unparasitized ones. The parasitoid also resulted in a significant mortality rate of pyrilla adults. The longevity of the surviving parasitized adults was prolonged in both sexes as against un-parasitized adults. The parasitoid F. melanoleuca had detrimental effects on host fitness and thus played a significant role as biocontrol agent in suppressing the pyrilla population as most of the parasitized individuals died before contributing to the next generation. These findings on understanding of host-parasitoid relationship may help in standardizing mass rearing methodology and optimizing an efficient augmentative biological control program against $P$. perpusilla in India. 


\section{Abbreviations}

ANOVA: Analysis of variance; SE: Standard error of means; Fig.: Figure.

\section{Acknowledgements}

The authors are grateful to Mrs. Jaswant Kaur Bindra fellowship assistance. We also thank Professor and Head, Department of Entomology, Punjab Agricultural University, Ludhiana, for providing necessary facilities.

\section{Authors' contributions}

TS contributed to experiment data collection and original draft writing. PSS contributed to conceptualization, planning and manuscript editing. All authors have read and agreed to the published version of the manuscript.

\section{Funding}

Not applicable.

\section{Availability of data and materials}

The datasets used during the current study are available from the corresponding author on reasonable request.

\section{Declarations}

Ethics approval and consent to participate

Not applicable.

\section{Consent for publication}

Not applicable.

\section{Competing interests}

The authors declare that they have no competing interests.

Received: 17 July 2021 Accepted: 21 October 2021

Published online: 27 October 2021

\section{References}

Akhtar MF, Gogi MD, Abbas Q, Shamraiz RM, Ahmed R, NiazT (2014) Impact of abiotic factors on population build-up of Pyrilla perpusilla and Epiricania melanoleuca on Sorghum. J Entomol Zool Stud 2:77-81

Anonymous (2019) Package of Practices for KharifCrops. pp 57. Punjab Agricultural University, Ludhiana

Bal RS, Dhaliwal ZS, Bains SS (1990) Biological effects of parasitism by Epiricania melanoleuca (Fletcher) on Pyrilla perpusilla (Walker). J Biol Control 4:77-79

Bindra OS, Brar RS (1978) Studies on the natural enemies of Pyrilla perpusilla Walker in the Punjab. Indian Sugar 28:247-252

Brar RS (1978) Role of natural enemies in the population dynamics of Pyrilla perpusilla Walker. Ph.D. dissertation. Punjab Agricultural University, Ludhiana, India

Brar RS, Bains SS (1979) Population dynamics of Pyrilla perpusilla Walker Mortality factors. Indian J Ecol 6:110-121

Cameron TC, Wearing HJ, Rohani P, Steven M, Sait SM, Memmott J (2005) A koinobiont parasitoid mediates competition and generates additive mortality in healthy host populations. Oikos 110:620-628

Chaudhary JP, Sharma SK (1988) Biological control of pyrilla using parasites and predators. In: David H, Easwaramoorthy S (eds) Biological technology for sugarcane pest management. Sugarcane Breeding Institute, Coimbatore, India, pp 186-206

Dhaliwal ZS (1982) Disruptive influence of abiotic factors and insecticides on the natural enemy complex of Pyrilla perpusilla (Walker) [Hemiptera:Lophopidae]. Ph.D. dissertation. Punjab Agricultural University, Ludhiana, India

Emeljanov AF (2018) A review of the fauna of the plant hopper family lophpopidae (Homoptera, Fulgoroidea) from Vietnam with descriptions of new genera and species and with taxonomic notes. Entomol Obozr 97:293-316

Farahani HK, Ashouri A, Zibaee A, Abroon P, Alford L (2016) The effect of host nutritional quality on multiple components of Trichogramma brassicae fitness. Bull Ent Res 106:633-641

Fennah RG (1963) The species of Pyrilla (Fulgoroidea:Lophopidae) in Ceylon and India. Bull Ent Res 53:715-735
Ganehiarachchi GASM, Fernando IVS (2006) Biology of Pyrilla perpusilla Walker (Homoptera: Lophopidae), a pest of sugarcane in the wet zone of Sri Lanka. J Entomol 3:26-33

Godfray HCJ (1994) Parasitoids: behavioral and evolutionary ecology. Princeton University Press, Princeton

Gupta BD (1940) On Epipyrops (sp.n.) — a parasite on the nymphs and adults of sugarcane leaf hopper (Pyrilla spp.). Curr Sci 9:132-133

Haeselbarth E (1979) Zur Parasitierung der Puppen der Forleule (Panolis flammea) [Schiff.]) und Heidelbeerspanner (Boarmia bistortana)[Goeze]) in bayerischen Kiefernwäldern. Á. Z. Angew Entomol 87: 186Á

Hagvar EB, Hofsvang T (1991) Aphid parasitoids (Hymenoptera: Aphidiidae): biology, host selection, and use in biological control. Biocontrol News Infor 12:3-41

Harvey JA, Kadash K, Strand MR (2000) Differences in larval feeding behavior correlate with altered developmental strategies in two parasitic wasps: implications for the size-fitness hypothesis. Oikos 88:621-629

Kohyama TI, Onizawa K, Kimura MT (2017) Growth rate adjustment of two Drosophila parasitoids in response to the developmental stage of hosts. Ecol Entomol 42:785-792

Kumar R, Mittal V, Chutia P, Ramamurthy W (2015) Taxonomy of Fulgoraecia melanoleuca (Fletcher, 1939), (Lepidoptera: Epipyropidae) in India, a biological control agent of Pyrilla perpusilla (Walker) (Hemiptera: Lophopidae). Zootaxa 3:431-439

Liang A (1997) Sugarcane and rice plant hoppers of the genus Pyrilla stal in Southern China (Insecta: Homoptera: Auchenorrhyncha: Lophopidae). Reichenbachia 32:33-39

Mahesh P, Srikanth J, Salin KP, Singaravelu B, Chandran K, Mahendran B (2019) Phenology of sugarcane leaf hopper Pyrilla perpusilla (Walker) (Homoptera: Lophopidae) and its natural enemies in a crop island scenario. Crop Prot 120:151-162

Misra MP, Krishna SS (1986) Variation in the reproductive performance of Epiricania melanoleuca (Fletcher) (Lep., Epipyropidae) in relation to stage and sex of the host Pyrilla perpusilla (Walker) (Horn., Lophopidae) during rearing. Anzeiger Fur Schadlingskunde, Pflanzenschutz Umweltschutz 59:20-21

Mukerji S, Venktaraman TV (1948) Studies on Epipyrops melanoleuca Fletcher (Lepidoptera: Epiloyropidae), and ectoparasite of sugarcane leafhopper, Pyrilla spp. (Homoptera: Fulgoridae). Proc Zool Soc Bengal 1:91-102

Neupane FP (1976) Studies on the effectiveness of different insecticides against the nymphs of sugarcane leaf hopper Pyrilla perpusilla (Walk.) Nepalese J Agric 6-11: 131-137

Puri KD, Sidharth K (2001) Effect of pyrilla epidemic (1999-2000) on sugarcane yield and sucrose. Proc 63rd Annual Convention on Sugar Technology Association, pp 60-68, New Delhi, India

Rajak DC, Singh RP, Tripathi RA, Kumar S (2006) Studies on the biology of Epiricania melanoleuca Fletcher a potent parasitoid for management of Pyrilla perpusilla Walker in sugarcane. Indian J Sugarcane Technol 21:49-53

Rasul A, Mansoor-Ul-Hassan FM, Khan RR (2014) Sustainable management of sugarcane Pyrilla, Pyrilla Perpusilla Wlk. (Homoptera: Lophopidae) by using cultural, chemical and biological practices in Punjab, Pakistan. Pak Entomol 36:45-49

Rohlfs WM, Mack TP (1983) Effect of parasitation by Ophion flavidus Brulle (Hymenoptera: Ichneumonidae) on consumption and utilization of a Pinto bean diet by fall armyworm (Lepidoptera: Noctuidae). Environ Entomol 12:1257-1259

Seneviratne JAUT, Kumarasinghe NC (2002) Biological control of the sugarcane plant hopper by the moth Epiricania melanoleuca (Fletcher) in Sri Lanka. Sugar Tech 4:26-32

Sharma T (2021) Host-parasitoid relationship between Pyrilla perpusilla (Walker) and Fulgoraecia melanoleuca (Fletcher) on sugarcane. M.Sc. thesis. Punjab Agricultural University, Ludhiana, India

Srikanth J, Easwaramoorthy S, Jalali SK (2016) A 100 years of biological control of sugarcane pests in India: review and perspective. CAB Rev. https://doi.org/ 10.1079/PAVSNNR201611013

Strand MR, Pech LL (1995) Immunological basis for compatibility in parasitoidhost relationships. Annu Rev Entomol 40:31-56

Yaseen L, Aslam A, Aslam M (2021) Predators and parasitoids of sugarcane crop in ecological zone of Rahim Yar Khan. Int J Adv Res Biol Sci 8:16-22

\section{Publisher's Note}

Springer Nature remains neutral with regard to jurisdictional claims in published maps and institutional affiliations. 